\title{
The Helicobacter pylori breath test: a surrogate marker for peptic ulcer disease in dyspeptic patients
}

\author{
K E L McColl, A El-Nujumi, L Murray, E El-Omar, D Gillen, A Dickson, A Kelman, \\ T E Hilditch
}

\begin{abstract}
Background-There is interest in noninvasive $H$ pylori testing as a means of predicting diagnosis and determining management in dyspeptic patients.

Aims-To assess the value of the ${ }^{14} \mathrm{C}$ urea breath test as a predictor of peptic ulcer disease in patients presenting with dyspepsia.

Patients and methods-327 consecutive patients referred for investigation of dyspepsia had a ${ }^{14} \mathrm{C}$ urea breath test performed before endoscopy. Patients were not included if they had previously confirmed ulcer disease, previous gastric surgery, or were taking non-steroidal anti-inflammatory drugs.
\end{abstract}

Results-Of the 182 patients with a positive ${ }^{14} \mathrm{C}$ urea breath test, duodenal and/or gastric ulcers were present in $\mathbf{4 5 \%}$ and erosive duodenitis in a further $2 \%$. Oesophagitis was present in $12 \%$ of the breath test positive patients with two thirds of the oesophagitis patients having co-existent ulcer disease. The prevalence of ulcer disease in the $H$ pylori positive dyspeptic patients was independently related to smoking and previous investigation status. If previously uninvestigated, the prevalence of ulcers was $67 \%$ in smokers and $46 \%$ in non-smokers. If previous upper gastrointestinal investigations were negative, the prevalence of ulcers was $53 \%$ in smokers and $28 \%$ in non-smokers. Of the 136 patients with a negative breath test, only $5 \%$ had peptic ulcers. The most frequent endoscopic finding in these $H$ pylori negative subjects was oesophagitis, being present in $17 \%$. Conclusions-This study demonstrates that a positive $H$ pylori test is a powerful predictor of the presence of underlying ulcer disease in dyspeptic patients, especially if smokers, and that a negative $H$ pylori test is a powerful predictor of the absence of ulcer disease. It also indicates that a negative upper gastrointestinal investigation does not preclude subsequent presentation with ulcer disease. (Gut 1997; 40: 302-306)

Keywords: Helicobacter pylori, dyspepsia, ${ }^{14} \mathrm{C}$ urea breath test, endoscopy, peptic ulcer.

Upper gastrointestinal endoscopy has become the predominant investigation in establishing the diagnosis and determining management in patients with dyspepsia. Over the past 20 years the use of endoscopy has increased continuously and it has been predicted that within the next few years $1 \%$ of the general population will undergo the examination every year. ${ }^{1}$ Providing this level of endoscopic service is expensive. In addition, the examination is not without discomfort to the patient.

The discovery of Helicobacter pylori infection has transformed treatment of peptic ulcer disease. It also has the potential to reduce the need for endoscopy in the management of dyspepsia. It has been proposed that patients presenting with simple dyspepsia should have non-invasive screening for $H$ pylori infection and only proceed to endoscopy if this is positive. $^{2-5}$ The rationale for this is that endoscopic examination is negative in the great majority of $H$ pylori negative subjects and when positive usually reveals only oesophagitis, which is managed by symptomatic treatment.

Another possible endoscope saving strategy is to perform non-invasive $H$ pylori screening in dyspeptic patients and then to eradicate the infection in all those positive and only proceed to endoscopy in those whose symptoms remain troublesome following successful eradication of the infection. The number of endoscopic examinations which might be saved by the latter approach will depend upon the proportion of $H$ pylori positive dyspeptic subjects who have underlying ulcer disease and whose cause of dyspepsia may therefore be cured by eradication therapy. At present there is relatively little detail concerning the prevalence of ulcer disease in $H$ pylori positive dyspeptic subjects.

We have undertaken a prospective study to assess the value of non-invasive $H$ pylori screening in predicting the presence of ulcer disease.

\section{Methods}

Patients

The study involved 327 consecutive patients seen at our dyspepsia clinic. This clinic accepts patients referred by general practitioners for investigation of intermittent or persistent dyspepsia. Dyspepsia is defined as upper abdominal or retrosternal pain, discomfort, heartburn, nausea, vomiting, or other symptoms considered to be referable to the proximal alimentary tract. ${ }^{6}$ The patients are 
seen at the clinic within 4 weeks of referral. Patients are excluded if they have undergone gastric surgery, have previously confirmed peptic ulcer disease, or are taking non-steroidal anti-inflammatory drugs (NSAIDs) (excluding low dose aspirin).

\section{Methods}

The patients reported for their initial clinic assessment following an overnight fast. They were interviewed about their dyspepsia and an abdominal examination was performed. The severity of their dyspepsia over the preceding 6 months was assessed by means of the Glasgow Dyspepsia Severity Questionnaire. ${ }^{7}$ This scores the severity of dyspepsia on a 0-20 scale. Immediately following this, the patients had a ${ }^{14} \mathrm{C}$ urea breath test to determine their $H$ pylori status. The patients were then given an appointment for upper gastrointestinal endoscopy which was performed within 2 weeks of their initial clinic visit.

Patients were told to avoid antibiotics, bismuth preparations, and antisecretory medication for at least 2 weeks before having their breath test and to remain off such medication until they had undergone the endoscopic examination.

The ${ }^{14} \mathrm{C}$ urea breath test involved drinking $240 \mathrm{ml}$ of Ensure Plus (Abbott, Maidenhead) to delay gastric emptying, followed by $0.4 \mathrm{MBq}$ ${ }^{14} \mathrm{C}$ urea in $20 \mathrm{ml}$ water. Samples of breath carbon dioxide were collected before administration of the isotope and at 20 minutes afterwards. The breath samples were analysed by liquid scintillation counting. Taking a 20 minute breath test value $(\mathrm{kg} \%$ dose $/ \mathrm{mmol}$ $\mathrm{CO}_{2}$ ) of $>40$ as positive and $<20$ as negative, the sensitivity and specificity of our breath test are both $>95 \%$ assessed against histology of antral and body mucosal biopsy specimens. ${ }^{8}$

\section{Statistical analysis}

When examining differences in the incidence of ulcer disease associated with the presence or absence of a risk factor, confidence intervals for the difference in the proportions were evaluated using the computer program CIA. ${ }^{9}$ Forward stepwise logistic regression using the statistical package SPSS for Windows was used to determine which factors were independently associated with ulcer disease.

\section{Results}

Four patients seen at the clinic either did not return for the endoscopy or were unable to tolerate the procedure and could not be included in the analysis. The mean age of the 327 subjects who underwent both the breath test and the endoscopy was 39 years (range 15-77 years) and $54 \%$ were females. The most common predominant presenting symptom was epigastric pain or discomfort $(61 \%$ of patients), second commonest was retrosternal discomfort $(19 \%)$, and the third was regurgitation (7\%). The predominant symptoms in the remaining $13 \%$ included nausea, flatulence, right upper quadrant discomfort, and left upper quadrant discomfort. The time interval from first noting dyspepsia until attendance at the clinic ranged from 4 months to more than 10 years with the median time of between 2 and 5 years. In all, 168 of the subjects had not had any previous upper gastrointestinal investigations. The other patients had undergone either barium meal, and/or endoscopic examinations which had shown no evidence of peptic ulcer disease.

A total of 182 of the patients had a 20 minute ${ }^{14} \mathrm{C}$ urea breath test value of $>40$, indicating the presence of $H$ pylori infection; 136 had a value of $<20$, indicating that they were $H$ pylor $i$ negative; nine patients had a value between 20 and 40 and were categorised as equivocal.

The findings at endoscopy were related to the result of the $H$ pylori breath test. The endoscopy was abnormal (excluding hiatus hernia) in only $21 \%$ of the breath test negative subjects compared with $52 \%$ of the breath test positive subjects. The nature of the positive endoscopic findings was also dependent upon the result of the breath test (Fig 1). In the 136 $H$ pylori negative subjects, 21 had oesophagitis alone, three duodenal ulcer (DU) alone, two gastric ulcer (GU) alone, and two GU and oesophagitis. In the 182 breath test positive subjects DU was present in $40 \%$, GU in $13 \%$, oesophagitis in $12 \%$, and erosive duodenitis in $2 \%$. There was considerable overlap of the diagnostic categories in these $H$ pylori positive subjects (Fig 1).

Forty seven per cent of the $H$ pylori breath test positive patients thus had underlying ulcer disease (gastric ulcer, duodenal ulcer, or erosive duodenitis), compared with only $5 \%$ of the breath test negative patients.

Further analysis indicated that two important determinants of the presence of ulcer disease in the $H$ pylori positive dyspeptic group were smoking status and previous upper gastrointestinal investigations (Table). If previously uninvestigated, the prevalence of ulcers was $67 \%$ in smokers and $46 \%$ in non-smokers. If previous upper gastrointestinal investigations were normal, the prevalence of ulcers was $53 \%$ in smokers and $28 \%$ in non-smokers (Fig 2).

In the $H$ pylori positive dyspeptic patients the prevalence of underlying ulcer disease was also higher in those with other recognised risk factors - namely, epigastric pain as predominant symptom, family history of ulcer disease, age $<45$ years, male sex, or symptom duration of more than 5 years, being $51 \%$, $54 \%, 52 \%, 51 \%$, and $52 \%$ respectively. The stepwise logistic regression analysis using the markers in the Table showed that smoking, previous upper gastrointestinal investigation, and duration of symptoms were statistically significant independent predictors of ulcer disease in the $H$ pylori positive subjects. Of note was the finding of lack of association between prevalence of underlying ulcers and either severity of dyspepsia or presence of epigastric tenderness on abdominal examination.

We did not undertake any formal assessment of the incidence of the subsequent 


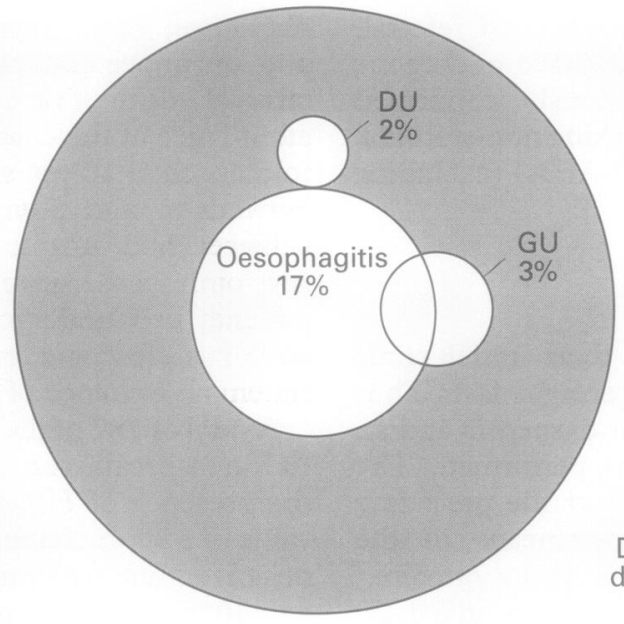

HP breath test negative $(n=136)$

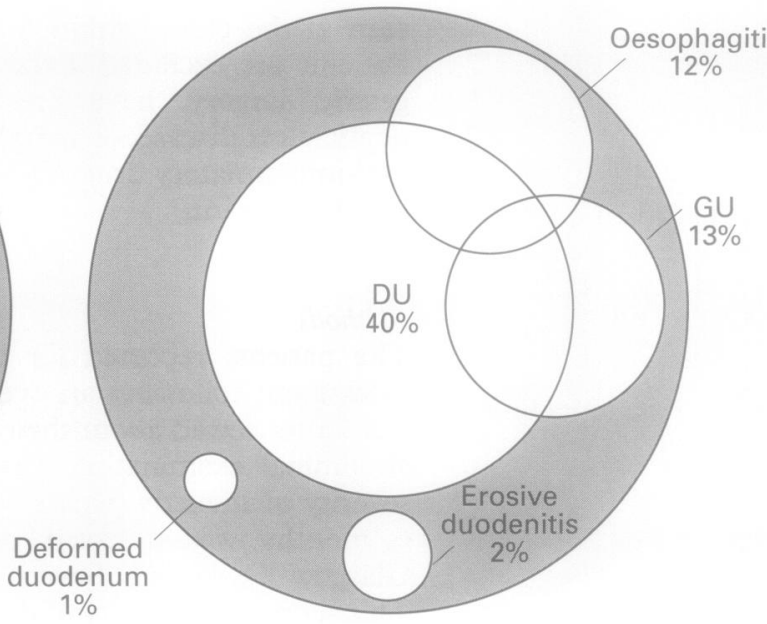

HP breath test positive

$(n=182)$

Figure 1: The influence of $\mathrm{H}$ pylori (HP) status on endoscopic findings in dyspeptic patients.

development of ulcer disease in the $H$ pylori positive dyspeptic subjects who had a normal endoscopic examination. However, it came to our notice that $5 \%$ of the $H$ pylori positive subjects with a normal endoscopy at the dyspepsia clinic were confirmed to have duodenal or pre-pyloric ulcer disease within the subsequent 6 months. These patients had been referred back for further investigation because of persisting severe dyspepsia or acute upper gastrointestinal bleeding.

Further analysis was performed in the seven subjects with ulcer disease and a negative breath test. Of the three duodenal ulcer patients with a negative breath test, one had $H$ pylori on examination of mucosal biopsy specimens whereas the other two had no

Prevalence of ulcer disease in subgroups of $\mathrm{H}$ pylori positive dyspeptic patients

\begin{tabular}{|c|c|c|c|}
\hline & \multicolumn{2}{|c|}{$\begin{array}{l}\text { Prevalence of } \\
\text { ulcer disease }\end{array}$} & \multirow{2}{*}{$\begin{array}{l}95 \% \text { Confidence } \\
\text { intervals for } \\
\text { difference in } \\
\text { prevalence rates }\end{array}$} \\
\hline & No & $\%$ & \\
\hline \multicolumn{4}{|l|}{ Smoking: } \\
\hline $\begin{array}{l}\text { Smokers } \\
\text { Non-smokers }\end{array}$ & $48 / 79$ & 61 & $11 \%$ to $39 \%$ \\
\hline \multirow{2}{*}{\multicolumn{4}{|c|}{$\begin{array}{l}\text { Previous upper GI } \\
\text { investigations: }\end{array}$}} \\
\hline & & & \\
\hline Normal & $35 / 93$ & 38 & $4 \%$ to $33 \%$ \\
\hline \multicolumn{4}{|l|}{ Age (years): } \\
\hline $\begin{array}{l}<45 \\
45+\end{array}$ & $\begin{array}{l}59 / 113 \\
26 / 69\end{array}$ & $\begin{array}{l}52 \\
38\end{array}$ & $0 \%$ to $29 \%$ \\
\hline \multicolumn{4}{|l|}{ Predominant symptom: } \\
\hline $\begin{array}{l}\text { Epigastric pain } \\
\text { Heartburn/regurgitation` } \\
\text { Other }^{\star}\end{array}$ & $\begin{array}{l}57 / 111 \\
18 / 46 \\
10 / 25\end{array}$ & $\begin{array}{l}51 \\
39 \\
40\end{array}$ & $-3 \%$ to $27 \%$ \\
\hline \multicolumn{4}{|l|}{ First degree relative } \\
\hline $\begin{array}{l}\text { Yes } \\
\text { No }\end{array}$ & $\begin{array}{l}39 / 72 \\
46 / 110\end{array}$ & $\begin{array}{l}54 \\
42\end{array}$ & $-2 \%$ to $27 \%$ \\
\hline \multicolumn{4}{|l|}{ Symptom duration (years): } \\
\hline $\begin{array}{l}>5 \\
\leq 5\end{array}$ & $\begin{array}{l}36 / 89 \\
49 / 113\end{array}$ & $\begin{array}{l}52 \\
43\end{array}$ & $-6 \%$ to $24 \%$ \\
\hline \multicolumn{4}{|l|}{ Sex: } \\
\hline $\begin{array}{l}\text { Male } \\
\text { Female }\end{array}$ & $\begin{array}{l}45 / 89 \\
40 / 93\end{array}$ & $\begin{array}{l}51 \\
43\end{array}$ & $-7 \%$ to $22 \%$ \\
\hline \multicolumn{4}{|l|}{ Severity of dyspepsia: } \\
\hline $\begin{array}{l}\text { Dyspepsia score } \leq 11 \\
\text { Dyspepsia score } \geq 12\end{array}$ & $\begin{array}{l}37 / 79 \\
48 / 103\end{array}$ & $\begin{array}{l}47 \\
47\end{array}$ & $-14 \%$ to $15 \%$ \\
\hline \multicolumn{4}{|l|}{ Abdominal examination: } \\
\hline $\begin{array}{l}\text { Epigastric tenderness } \\
\text { Normal }^{\star}\end{array}$ & $\begin{array}{l}16 / 39 \\
61 / 130\end{array}$ & $\begin{array}{l}41 \\
47\end{array}$ & $-25 \%$ to $10 \%$ \\
\hline Other $^{\star}$ & $8 / 13$ & 62 & \\
\hline
\end{tabular}

${ }^{\star}$ Combined in statistical analysis. $\mathrm{GI}=$ gastrointestinal.

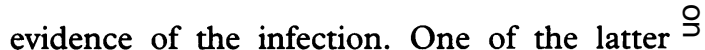
patients subsequently admitted to taking $\overrightarrow{3}$ amoxycillin at the time of her investigations. Of the four gastric ulcer patients with negative $\frac{\text { S }}{3}$ breath tests, only one had evidence of $H$ pylori $\vec{\bullet}$ on mucosal biopsy specimens. One of the $H$ pylori negative gastric ulcer patients subsequently admitted to taking the NSAID, azapropazone. Only one of the seven breath test negative ulcer patients was a smoker despite the prevalence of smoking in the entire $\stackrel{\circ}{\circ}$ 136 breath test negative subjects being $30 \%$.

The nine patients with equivocal breath test $\frac{0}{3}$ values $(>20,<40)$ were not included in the formal analysis described above. Separate analysis was undertaken of their $H$ pylori status and endoscopic diagnosis. Examination of $\subsetneq$ their antral and body mucosal biopsy specimens showed evidence of $H$ pylori in six of them (breath test values 21,23,29, 31, 34, 약 38 ) and no evidence of the organism in the three (breath test values $21,24,31$ ). The only ? endoscopic abnormality in these nine patients $\frac{7}{0}$ was a duodenal ulcer in one patient whose breath test value was 31 and who had $H$ pylori $\stackrel{N}{\sigma}$ on examination of mucosal biopsy specimens.

Discussion

This study demonstrates the value of non- $\frac{0}{\Phi}$ invasive $H$ pylori testing in predicting the $\stackrel{?}{?}$ endoscopic diagnosis in patients presenting $\underset{T}{0}$ with dyspepsia. Seventy nine per cent of those $\frac{\vec{D}}{\mathrm{O}}$

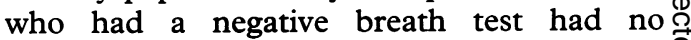
abnormality at subsequent endoscopy. The $\stackrel{\mathbb{D}}{\mathscr{Q}}$ endoscopic diagnoses in the remaining $21 \%$ Q consisted mainly of oesophagitis with only $5 \%$ o having peptic ulcers. Our findings in the breath test negative dyspeptic subjects are very similar to the results previously reported by the Leeds group and the St George's group using $H$ pylori serology as the non-invasive screening test. ${ }^{2-5}$

The present study demonstrates additionally the value of a positive $H$ pylori test in predicting the presence of ulcer disease in dyspeptic patients. Overall, $47 \%$ of such subjects were found to have evidence of duodenal ulcers, 


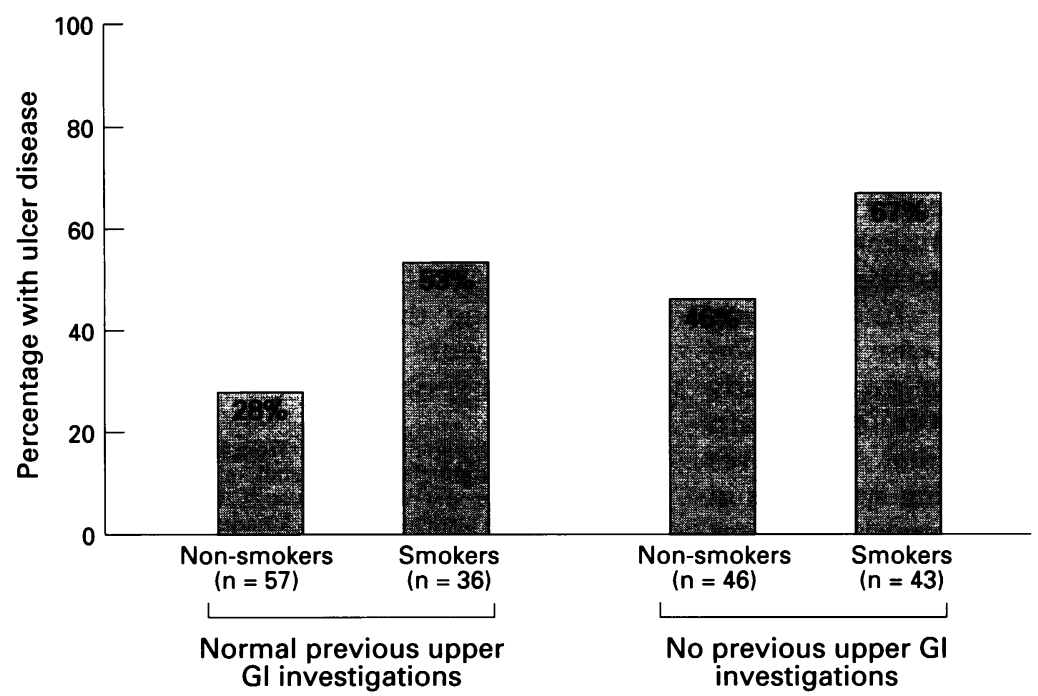

Figure 2: Prevalence of ulcer disease in $\mathrm{H}$ pylori positive patients classified according to smoking status and previous upper gastrointestinal (GI) investigations.

gastric ulcers, or erosive duodenitis. The presence of other recognised risk factors for ulcer disease (smoking, family history of peptic ulcer disease, epigastric pain as predominant symptom, age $<45$ years, male sex, and prolonged duration of symptoms) further increased the prevalence of the ulcer disease with combinations of risk factors increasing the prevalence even further. The two most important and independent determinants of the prevalence of ulcer disease in the $H$ pylori positive dyspeptic patients were smoking and previous investigation status. In those previously uninvestigated the prevalence of ulcers was $67 \%$ in smokers and $46 \%$ in nonsmokers. Though the prevalence of ulcers in the $H$ pylori positive dyspeptic subjects with previous normal upper gastrointestinal investigations was lower, it remained substantial, being $53 \%$ in smokers and $28 \%$ in non-smokers. This high prevalence of ulcer disease in those with previous normal upper gastrointestinal investigations may be the result of them developing ulcer disease subsequent to that investigation or as a result of their ulcer disease having been missed at the earlier investigation, possibly because of masking by antisecretory medication.

In the $H$ pylori positive group there was no association between the severity of dyspeptic symptoms and the presence of ulcer disease. In addition, and perhaps more surprisingly, we could find no association between the presence of epigastric tenderness on abdominal examination and underlying ulcer disease.

Though the prevalence of detected ulcer disease in the $H$ pylori positive dyspeptic subject seems remarkably high, it is still an underestimate of the incidence of ulcer disease in such subjects. Five per cent of the $H$ pylori positive dyspeptic patients who had a normal endoscopy at our clinic were found to have actual ulceration at repeat endoscopy within the subsequent 6 months. This is consistent with our finding that a substantial proportion of the patients with previous normal upper gastrointestinal investigation were found to have ulcers at the current examination. Again, it is unclear whether such patients represent missed ulcers as a result of masking by acid inhibitory agents or the subsequent development of ulcer disease. Taken together, this indicates that the majority of the $H$ pylori positive patients with dyspepsia had or were developing underlying ulcer disease.

It may be argued that this high prevalence of ulcer disease in $H$ pylori positive dyspeptic patients is unique to the west of Scotland. The prevalence of ulcer disease in this region is known to be about twice that in England. ${ }^{10}$ However, the prevalence of $H$ pylori infection in Glasgow is $66 \%$ which is also about twice that of England. ${ }^{11}$ This suggests that the percentage of $H$ pylori positive patients developing ulcer disease is similar in the different regions of the country. Preliminary results of studies performed in the south east of England indicate a similarly high prevalence of ulcer disease in $H$ pylori positive dyspeptic subjects. ${ }^{12}$ Studies in the United Kingdom before the recognition of $H$ pylori infection reported a prevalence of ulcer disease in patients investigated for dyspepsia of approximately $20 \% .^{13}$ When a correction is made for the fact that less than half of these subjects would have been positive for $H$ pylori and virtually all the ulcers would be in that subgroup, then the prevalence of ulcer disease in those $H$ pylori positive dyspeptics would be approximately $50 \%$ and thus similar to the finding of our study.

It should be highlighted that the present study examined patients with dyspepsia of sufficient severity to merit referral for endoscopy. The prevalence of ulcer disease in $H$ pylori positive dyspeptic patients who have never sought medical advice or who have attended their general practitioner but have not been referred for investigation may be different.

The present study also demonstrates the low prevalence of ulcer disease in patients with a negative $H$ pylori test. Only seven (5\%) of the patients with a negative breath test were found to have peptic ulcers. Further studies indicated that two of these had $H$ pylori on examination of gastric mucosal biopsy specimens and a third patient had been taking amoxycillin which would have given a false negative breath test result. Of the four remaining patients with true $H$ pylori negative peptic ulcers one subsequently admitted using a NSAID. This very low prevalence of true $H$ pylori negative peptic ulcers is consistent with previous studies and the recognised association with NSAIDs. ${ }^{14}$

Next to $H$ pylori infection, smoking was the most powerful acquired factor in predicting ulcer disease. However, the influence of smoking was confined to the $H$ pylori positive subjects. Indeed, only one of the seven breath test negative ulcer patients smoked, despite the prevalence of smoking in the entire group of breath test negative subjects being $30 \%$. Smoking thus seems to act as a facilitator of ulcer disease rather than an initiator.

The ability of non-invasive $H$ pylori testing to predict with some confidence the diagnosis in 
dyspeptic patients raises the possibility of such testing being used in place of endoscopy in order to determine management in young patients with uncomplicated dyspepsia. It has been proposed that such dyspeptic patients with a negative $\boldsymbol{H}$ pylori test could merely be prescribed sympthmatic treatment and not subjected to endoscopy owing to their very low prevalence of ulcer disease. ${ }^{3412}$ In confirming the low prevalence of ulcer disease in $H$ pylori negative dyspeptic patients our present study supports such a strategy. However, one concern about such an approach is that it involves managing patients with persisting symptoms in the absence of a definitive diagnosis. Previous studies have highlighted the value of a negative endoscopy in reassuring the patient and doctor of the absence of serious disease and in guiding future management. ${ }^{15} 16$

The other way in which non-invasive $H$ pylori testing might replace endoscopy is by administering $H$ pylori eradication therapy to all patients with simple dyspepsia who test positive for $H$ pylori and only proceeding to endoscopy in those whose symptoms persist despite successful eradication of the infection. One concern about this "eradicate first" approach is the fact that the majority of $H$ pylori positive dyspeptics would not have underlying ulcer disease and thus be receiving treatment which would not improve their symptoms but could cause them significant side effects. However, our finding of the high prevalence of underlying peptic ulcer in $H$ pylori positive dyspeptic patients provides support for such an approach especially if it is used in patients with additional risk factors for ulcer disease - for example, smokers or those without previous normal investigations.

Imaging of the upper gastrointestinal tract by endoscopy or barium meal is often regarded as a definitive investigation in confirming or excluding ulcer disease in dyspeptic patients. However, our finding of ulceration in a substantial proportion of the patients with previous normal upper gastrointestinal investigation indicates that a single such examination is an unreliable way of permanently classifying the patient as having nonulcer disease. In the debate about the relative merits of endoscopy versus $H$ pylori testing in predicting ulcer disease it must be remembered that endoscopy is not a "gold standard". Endoscopy may underestimate the presence of ulcer disease owing to the relapsing and remitting nature of the condition, its subsequent development with time, and the masking effect of antisecretory therapy.

In summary, this study confirms the value of non-invasive $H$ pylori testing in predicting underlying ulcer disease in patients referred for investigation of dyspepsia. The ability of noninvasive $H$ pylori testing to replace endoscopy in determining the management of patients presenting with uncomplicated dyspepsia음 needs to be assessed.

This study was supported by a grant from the Medical Research $\overparen{D}$ Council. We are grateful to the staff of the Department of Nuclear Medicine who performed the ${ }^{14} \mathrm{C}$ urea breath tests.

This work was presented at the American Gastroenterology Association in San Francisco, May 1996.

1 Provision of gastrointestinal endoscopy and related services for aç district general hospital. Report by Working Party of British Society of Gastroenterology, 1990.

2 Sobala GM, Crabtree JE, Pentith JA, Rathbone BJ, $\overrightarrow{0}$ Shallcross TM, Wyatt JI, et al. Screening dyspepsia by $\omega$ serology to Helicobacter pylori. Lancet 1991; 338: 94-6.

3 Patel P, Khulusi S, Mendall MA, Lloyd R, Jazrawi R, Maxwell JD, et al. Prospective screening of dyspeptic $N$ patients by Helicobacter pylori serology. Lancet 1995; 윽 346: 1315-8.

4 Patel P, Mendall MA, Khulusi S, Molineaux N, Levy J, $\vec{Z}$ Maxwell JD, et al. Salivary antibodies to Helicobacter pylori: screening dyspeptic patients before endoscopy. Lancet 1994; 344: 511-2.

5 Mendall MA, Gogin PM, Marrero JM, Molineaux N, Levy J, Badve S, et al. Role of Helicobacter pylori serology $\vec{\theta}$ in screening prior to endoscopy. Eur $\mathscr{f}$ Gastroenterol Hepatol 1992; 4: 713-7.

6 Colin-Jones DG, Bloom B, Bodenov G, Crean G, Freston J, Malagelada J, et al. Management of dyspepsia. Freston J, Malagelada J, et al. Management of dysp

7 Eeport of a working party. Lancet 1988; Glasgow Dyspepsia Severity Score - a new tool for measuring the clinical and personal impact of dyspepsia. Gut 1994; 35 (suppl 5): S2.

8 Neithercut WD, Milne A, Chittajallu RS, Nujumi AM El, McColl KEL. Detection of Helicobacter pylori infection $\overline{\bar{\sigma}}$ of the gastric mucosa by measurement of gastric aspirate ammonium and urea concentrations. Gut 1991; 32: 973-6.

9 Gardner MJ, Altman DG, eds. Statistics with confidence -O confidence intervals and statistical guidelines. London: BMJ Publishing Group, 1989.

10 Knill-Jones RP. Geographical differences in the prevalence of dyspepsia. Scand $\mathcal{F}$ Gastroenterol 1991; 26 (suppl 182): 17-24.

11 Eurogast Study Group. An international association between Helicobacter pylori infection and gastric cancer. Lancet 1993; 341: 1359-62.

12 Mendall MA, Asante M, Patel P, Badve S, Finlayson C, Maxwell JD, et al. Do most patients with $\mathrm{H}$ pylori응 associated dyspepsia have duodenal ulcer disease? Gut 1995; 37 (suppl 2): A6.

13 Richter JE. Dyspepsia: organic causes and differential characteristics from functional dyspepsia. Scand $\hat{f}_{\mathrm{N}}$ Gastroenterol 1991; 26 (suppl 82): 11-16.

14 McColl KEL, El-Nujumi AM, Chittajallu RS, Dahill SW, Dorrian CA, El-Omar E, et al. A study of the pathogenesis of Helicobacter pylori negative chronic duodenal $\omega$ ulceration. Gut 1993; 34: 762-8.

15 Jones R. What happens to patients with non-ulcer dyspepsia after endoscopy? Practitioner 1988; 232: 75-8.

16 Johannessen T, Peterson $\mathrm{H}$, Kleveland PM, Dybdahl $\mathrm{JH}$, Sandvik AK, Brenna E, et al. The predictive value of $\mathbb{D}$ history in dyspepsia. Scand $f$ Gastroenterol 1990; 25:-? 689-97. 